\title{
Moral distress experienced by intensive care nurses
}

\author{
G C Langley, PhD; L Kisorio, PhD; S Schmollgruber, PhD
}

Department of Nursing Education, Faculty of Health Sciences, University of the Witwatersrand, Johannesburg, South Africa

Corresponding author: S Schmollgruber (shelley.schmollgruber@wits.ac.za)

Background. Moral distress is experienced when nurses experience conflict while making an ethical decision. This is magnified when the decisions are about withholding or withdrawing life-sustaining treatment.

Objective. To explore and describe nurses' experiences of situations that involve end-of-life care and evoke moral distress in the intensive care units (ICUs) of two public tertiary-level hospitals in South Africa (SA), the personal consequences of these situations and the means employed to manage their distress.

Methods. An exploratory, descriptive design was used. A short survey/interview guide was administered to registered and enrolled nurses $(N=100)$ employed in the ICUs from two academic-affiliated, specialist public hospitals.

Results. A total of 65 completed surveys were collected. Of these, 32 responses were judged not to be describing moral distress while 33 clearly described moral distress and were included and analysed by means of initial content analysis. The findings were presented in five major categories: (i) collegial incompetence or inexperience; (ii) resource constraints; (iii) end-of-life issues; (iv) lack of consultation, communication and negotiation; and ( $v$ ) support.

Conclusion. The study found that nurses experienced considerable moral distress. This is compounded in an environment where gender, professional and social status inhibit the nurses' assertiveness, 'voice' and influence in the healthcare system. Parallels can be drawn between the microcosm of the ICU and the macrocosm of the SA social and ethical character.

S Afr J Crit Care 2015;31(2):36-41. DOI:10.7196/SAJCC.2015.v31i2.235

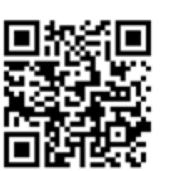

It has long been recognised that moral distress may be experienced by all health practitioners when a grave decision has to be made, when personal or team conflict arises or when constraints make it difficult or impossible to follow the perceived correct course of action. ${ }^{[1]}$ This distress may be expressed in physical and emotional ways, e.g. guilt, anger, feelings of poor self-worth, frustration, depression, spiritual distress, insomnia, nightmares and absenteeism.

Because active treatment and end-of-life decisions are mostly made by doctors, the medical perspective of cure is frequently emphasised and that of nursing and caring, marginalised. Nurses are involved in the care of critically ill and dying patients, their mandate being to provide patient and family-centred care in intimate and often intense situations such as in the intensive care unit (ICU). ${ }^{[2]}$ In this heightened emotional climate, ethical decisions have to be made that may be contested or divisive within the multidisciplinary healthcare team. ${ }^{[3]}$ End-of-life care (EOL) in particular has long been recognised as engendering moral distress due to the situations inherent in caring for a dying person. ${ }^{[1,4-11]}$

A study conducted in Johannesburg level 1 ICUs revealed that $33 \%$ of the nurse participants felt that decisions to withdraw active treatment were made too late. ${ }^{[12]}$ Distress may also be experienced when the expectations of family members are unrealistic or not in the patient's best interests, when patient safety is compromised ${ }^{[13]}$ or when the medical team overrides the patient's or family's wishes. ${ }^{[14]}$ Compassion fatigue is commonly found in staff caring for patients and their families faced with critical illness and death. ${ }^{[15]}$ Furthermore, the ethical sensitivity of the carer appears to be proportionate to the distress experienced. ${ }^{[1]]}$

Anger, anxiety, sadness, depression, guilt, frustration and feelings of helplessness and hopelessness may signify distress. ${ }^{[9,16,1]]}$
Physical symptoms may include gastrointestinal effects, headaches, palpitations, insomnia and nightmares. ${ }^{[18,19]}$ Socially, withdrawing from friends and family, and substance abuse have been cited. ${ }^{[19]}$ Professionally, a reluctance to interact with patients' families, limiting care, and absenteeism or leaving the unit, the hospital or even the profession have been noted as a result of moral distress. ${ }^{[3,9,14,16]}$

Despite the causes of and responses to moral distress being extensively reported, the South African ( $\mathrm{SA}$ ) healthcare system merits further exploration as it is conceivable that the SA context would add unique stressors to the ICU environment. The country is considered to have one of the world's most unequal economies, with a Gini coefficient measuring 0.58 ; the population unemployment rate is estimated to be between 25 and $35 \%{ }^{[20]}$ Marked wage inequalities exist within the workplace.

Public provincial hospitals are managed by SA provincial health departments and cater for the majority of the population. The mortality rate in ICUs varies from 20 to $40 \%{ }^{[2]}$

Poverty-related diseases, chronic diseases, a high incidence of violence and injuries are compounded by the presence of HIV/AIDS and tuberculosis. ${ }^{[2,23]}$

Negative media portrayal of nursing, the quality of nurse education and nursing graduates, and the acute shortage of nurses also cause anger and concern among the general public.

A tension exists between the medical staff (appointed jointly by the university and the provincial health department) and the hospital management and provincial authorities who administer the facilities and also employ the nursing staff members. Strained management-employee and nurse-physician relationships and competing expectations from all involved affect the emotional and moral climate. ${ }^{[24]}$ Economic inequality and differences in ethnicity (the majority of nurses are black women), gender, social status, culture, spiritual values, education (most nurses are educated in nursing 
colleges $v$. doctors at university) and professional socialisation are exacerbated in the acute-care environment and add to the potentially fraught situation. ${ }^{[25]}$ Relationships are strained as authorities attempt to implement government policy in a climate of political interference, deteriorating infrastructure, corruption and wasting of public resources. A poor ethical climate is not conducive to moral equilibrium and ethical composure. ${ }^{[25,26]}$

\section{Method}

The study was passed by the University of the Witwatersrand Human Research Ethics Committee (M121136), the hospitals and the relevant provincial authorities. After informal discussions in the relevant units, an information letter inviting participation and the data collection instrument were distributed to the total population $(N=100, n=100)$ of registered and enrolled nurses in the ICUs of two major specialist hospitals.

The instrument used comprised open-ended questions requiring narrative descriptions and explanations, and was derived from Corley et al.'s ${ }^{[16]}$ Moral Distress Scale. Those invited to participate could decline participation or withdraw at any time without consequence. Posting the completed instrument in a sealed box would indicate consent to participate and ensure anonymity. A blank questionnaire indicated a wish to refuse participation. Collection boxes were emptied on a weekly basis over 4 weeks. An offer of counselling with independent counsellors was included should the participants find the participation experience emotionally distressing. Many participants attached extra pages to the instrument to describe complex situations - some commenting that the experience of writing their stories had been cathartic.

Four focus group discussions of 45 minutes - 1.5 hours each with a minimum of six nurse participants (six to nine members per group) were also conducted. Members were invited from the same ICUs in order to expand upon or give greater depth to the written responses obtained in the survey and on the understanding that while in-group confidentiality was urged, anonymity could not be guaranteed. The members were persons who accepted the invitation to participate and no effort was made to establish whether they had also participated in the survey. Verbatim transcripts from these groups with added field notes augmented the written narratives and ensured data triangulation.

Lincoln and Guba's ${ }^{[2]}$ four criteria for qualitative data gathering, namely credibility, dependability, confirmability and transferability were applied to ensure trustworthiness. As the researchers are considered the 'instruments' in qualitative studies, ${ }^{[28]}$ it should be noted that the authors are experienced in the use of qualitative methods at a postgraduate level. All three were known in and had conducted studies in these ICUs. By virtue of their being accepted by the staff, they received assistance from the nursing and medical staff, thus meeting the requirement for prolonged engagement in the setting.

Excerpts from the written narratives are given in this article to illustrate the data presented and to enhance data credibility. Neutrality is achieved by providing narratives faithful to the participants' written stories and providing evidence of deviant as well as typical accounts. ${ }^{[2]}$

A definition of moral distress, constructed by the authors from different published sources, was given to guide the participants, namely:

A conflict which arises in certain circumstances to do with patient care, which occurs:
- when one knows or believes what the correct thing would be to do but can't pursue this option $O R$

- when either of two responses might be appropriate to a situation, both of which are not considered ideal.

Demographic information required included only the participants' qualification: registered nurse with an ICU qualification (diploma or degree in critical care); registered nurse with ICU experience; Registered nurse and ICU student; or enrolled nurse.

Participants were invited to respond to three open-ended questions:

- What situation/issue concerning the care of a critically ill or dying patient have you experienced which has caused you to feel morally distressed?

- What did you experience physically, mentally (thoughts), emotionally (feelings) or behaviourally (that is, your actions) which you consider due to the effects of this experience?

- How did you manage the feelings or thoughts in order to reassure/ soothe yourself or regain your composure?

\section{Analysis}

A total of 65 completed surveys were collected and numbered sequentially. An initial content analysis evaluated the responses. Thirty-two written responses clearly described emotional distress: sadness or distress in response to death of a patient or when comforting newly bereaved families; they were set aside and not analysed in this study. Thirty-three responses clearly described moral distress where a decision or action was experienced as infringing upon moral beliefs or ethical values held; these were included for analysis.

Data were then augmented with transcript material discussing moral distress from the focus group discussions and field notes that expanded on the focus group process. The data were categorised according to the situations or issues engendering distress, the experiences of the nurses, their actions taken, any ensuing effects and the manner in which the nurses dealt with these effects. This was a recursive process that involved going between tentative categories and returning repeatedly to the data, discussion, and continued refinement and positing of themes. Data were deemed sufficiently saturated when it was obvious that no new information would be obtained and that negative cases had been identified.

\section{Results}

Findings are presented under the five major themes elicited, which evoked moral distress: (i) collegial incompetence or inexperience; (ii) resource constraints; (iii) lack of consultation, communication and negotiation; (iv) end-of-life issues: maintaining futile care or withdrawing treatment; and $(v)$ support. Where quotes are given to illustrate the theme or subtheme, the source will be given as $B$ (for hospital 1), C (for hospital 2) or FG (for quotes taken from the focus group interview transcripts. Qualification and experience are noted where the information was given in the responses.

\section{Theme 1: Collegial incompetence or inexperience}

Perceived incompetence of colleagues was a source of considerable moral distress, particularly when deemed to threaten the integrity of the patient. Doctors, 'agency' nursing staff and students were among those considered to have insufficient knowledge or experience. This problem was mentioned by all participants in 
conjunction with the complaint of a shortage of staff. Nurses felt unable to confront or rectify the situation due to the hierarchical nature of the doctor-nurse relationship, the prevailing shortage of staff or their own inadequacy.

One registered ICU nurse told of nursing students who repeatedly failed to insert an intravenous (IV) line:'They should have told me that they didn't know. That was unfair, I was very worried' (C5). Another said: '... inexperienced nurse, critically ill patient, not even getting support from senior staff' (C13). Two ICU students (C12 and 7) stated that they were inadequately prepared but unable to ask for help as they were the only registered nurses available to care for the patients despite their inexperience.

An ICU registered nurse admitted to neglecting her patient: 'I got back ... his condition had deteriorated, blocked ET tube, SATS less than 80 , hypotensive, bradycardia. I was frightened and depressed. His safety was compromised because of staff shortage. Afterward I wasn't able to concentrate' (B22).

Ten of the thirteen responses mentioned doctors causing moral concerns. Generally, doctors were not challenged even when their inexperience was obvious. One participant recounted that the doctor 'gave scoline (succinylcholine) and then couldn't intubate. I was running around seeking help from the anaesthetic department' (C1). It is interesting that the participant did not assert any authority, but deferred to the doctor and did not take over and insert an endotracheal tube personally.

An ICU nurse said '... gunshot abdomen and lost so much blood. I advised her to increase the fluids but she wouldn't listen. I just gave in, I was submissive, just followed orders, I did nothing actually!' (C3). The regret and guilt in the narrative are obvious.

Another registered nurse (C8) said that she felt emotionally exhausted when many patients died after being operated on by a particular surgeon. She alerted the hospital management about her concern. An ICU nurse (B18) told of doctors who wouldn't review the treatment of a confused patient but prescribed sedation (haloperidol) and mechanical restraint. She finally persuaded them to examine the patient: '... his vocal chords were paralysed! Some patients die because we fail to diagnose them properly.'

An ICU nurse (B16) felt that she hadn't been sufficiently insistent when a junior consultant refused to move a badly burned patient to a specialised unit despite the nursing staff's urging. The patient died.

Another ICU nurse (C7) recounted that a postoperative patient was pale, in pain and bleeding from the IV site. 'So I asked about his history. He said he used to bleed when he was a child ... the doctors didn't ask'. He exanguinated and she said that she still has nightmares, feels guilty, frets about the patient's family and doesn't trust doctors.

An ICU nurse (B5) described how a doctor who had repeatedly failed to insert an arterial line 'writes a lie inside patient notes - that failure is due to lack of equipment. I felt frustrated!' She regretted that she didn't challenge the doctor's explanation, stop the procedure or call a more experienced physician. Truthfulness is an ethical norm and hallmark of professional behaviour ${ }^{[4]}$ and lying about the reasons for the failure of an intervention is likely to engender moral distress in colleagues. In their Canadian study, Pauly et al. ${ }^{[26]}$ found that competency of self and other healthcare providers emerged as key issues associated with moral distress.

\section{Theme 2: Resource constraints}

Staff shortages were a common problem that caused both anger and moral distress, because it was perceived that the patients'lives were jeopardised. One ICU nurse (C6) explained: 'Absenteeism, sickness, family responsibilities ... I feel emotionally exhausted and guilty. Patient care compromised, no shift leader, no overall supervisor.' Another senior ICU nurse (B3) wrote: '... using nursing assistants or grabbing anyone who calls herself ICU experience (sic) as long as there is someone in front of the patient. You get burned out, lose faith in people in charge; I am accountable, my profession at risk.

Because of the shortage of staff in provincial hospital units, agency nurses are used to ensure a minimum level of staffing. In some cases the shift leader was the only permanent member of staff and often the only qualified ICU nurse. The responsibility for the whole unit and the practice of others evoked anxiety, anger and a perception that they, as registered staff members, were being abused: '... coming to ICU not trained, also lacking experience; one called a cardiac monitor a ventilator! I'm emotionally exhausted seeing patients at risk in unsafe hands!' (C2). Many nurses 'moonlight' to supplement their income and request to work in ICU, relying on the expertise of the permanent staff to cover their inadequacies. The nurse in charge is likely to fear for the patients' welfare in the hands of unqualified or inexperienced colleagues. Only one participant mentioned that she had complained to the hospital management with good effect.

Increasingly the concept of 'skills mix' is used, with subprofessional staff (enrolled nurses) being brought in to care for patients for financial reasons or to augment the number of professional nurses. One ICU nurse (B15) said: '... eight beds, enrolled nurses only, some of them not even experienced and the patients (are) sick! I had a critical patient myself. I felt mentally and physically exhausted. I was angry - one nurse accused me of following her around, checking on her!'

Adequate staffing levels with competent, registered nurses has been identified as important in ensuring safe patient care and addressing the intensity of moral distress. ${ }^{[26]}$

\section{Theme 3: Lack of communication, consultation and negotiation}

Two participants in the survey group and three in the focus group discussions said that the need to communicate with family members evoked moral distress: '... they're a challenge. They still have hopes and want to hear something different ... they've been told by the doctor but they still come and ask you. Miracles do happen so you can't say the patient will die' (FG2). Many exhibited a strong religious or fatalistic point of view, and spoke of prayer as a means of coping with their distress or rationalised the death of patients by referring to God as the ultimate arbiter of life and death.

However, one study has demonstrated that registered nurses were able to identify situations of futile care more often than doctors. ${ }^{[30]}$ If this is so, moral distress may be experienced as the nurse tries to align his or her deeply felt personal beliefs with their professional knowledge and experience, and with that of the medical staff and the hopes of the family.

The difficulty of caring for the family after the patient's death is illustrated by one nurse (FG12), who said: 'the family sit (at the dead person's bedside), I run around looking for a shroud. There is no time - the surgeon has already asked for a bed.' In the same transcript another nurse said: 'while they're still there, I'm looking for the pump and bringing in the admission that is coming for the bed!'

A focus group participant (FG10) said: 'Sometimes the nurses disappear - they don't want to be asked questions.' This was echoed 
by an experienced registered nurse (C14): 'I have decided to keep quiet, only speak when necessary, they don't accept the condition. It is disheartening to try and convince them.' This avoidance is concerning as a nurse cares for both the patient and the family. When talking to the patient is not possible, it is the family who need information, reassurance and guidance on the process of dying. Pauly et $a l^{\left[{ }^{[2]}\right.}$ note that moral distress may manifest behaviours such as avoiding or withdrawing from patients.

Another ICU nurse (B6) spoke of the family being angrily divided about the decision to terminate treatment. She also disagreed with the decision but had to explain why she was switching off the ventilator. This situation was particularly difficult because '... there is a patient with a good prognosis who needs to be admitted to the same cubicle. This is very difficult. You've maybe failed, maybe you were not competent enough'. Gutierrez ${ }^{[14]}$ and Fry et al. ${ }^{[18]}$ assert that persons experiencing moral distress experience a decrease in their self-esteem and self-confidence and tend to blame themselves.

The lack of team communication was a common problem. One focus group participant (FG5) reported: 'Doctors just go ahead and do their own thing; you don't matter.' Another (FG2) in the same focus group agreed: 'No, you don't argue'.

Poor communication also included team members ignoring suggestions for treatment. A registered ICU nurse (B19) recounted how she had pressed a doctor to intervene urgently but her advice was discounted. 'I felt demotivated ... my contribution was ignored, the patient could lose his kidney.' Despite the rebuff, she called the nephrology consultant and asked him to initiate treatment. 'Doctors must understand that ICU nurses have worked with these patients.' She was one of the few participants who stated that they had acted autonomously.

In addition to feeling that their advice was ignored, nurses also verbalised that they wanted to be included when decisions were made. II shouldn't feel like I'm being left out and just being told; I need to understand!' (FG6).

All but one participant stated that they wished that they had been consulted or included in the discussion leading to the decision to withdraw active treatment; only two of the participants stated that they had been involved but explained that they were included only because they were in a position of authority. Another two wrote that they had requested that they be involved in end-of-life discussions when they were caring for the patient under consideration. This lack of communication may lead to fundamental differences in perception. For example, a teenage girl had sustained irreparable brain damage. Active treatment was terminated without consulting or informing the child's family but ventilation and cardiac monitoring were continued. Only later was the family asked for consent for organ donation. The nurse (B25) said: 'Doctors only care for organ donors this for me is a crisis of conscience'. The decision and management of the case was probably ethical and correct; however, it appears that the nurses were not included in the decision and this nurse felt that they and the family should have been consulted before the decision was made. However, the processes of who negotiates with whom and when also need to be agreed upon, as some nurses do not wish to be part of the deciding team: 'I'm not God. I wouldn't like to be included when the family still have hope' (FG6).

One nurse (B15) felt defeated when the consultant countermanded the doctor's and her recommendations: 'So we were blamed for the death; we tried but that is how it is, somebody has to be blamed'. Schluter et al. ${ }^{[25]}$ comment that unsuccessful attempts to advocate for patients engender strong feelings of moral outrage and moral distress.

The hierarchical structure of the healthcare system is demonstrated in the above section. Nurses need to be advocates for their patients and the families. They are the professionals who are in a position to observe the patient's status and manage or adjust the complex interventions. They are also the members of staff who are in a position to interact with and give information and reassurance to family members. However, very few participants in this study felt empowered to act autonomously or challenge the lack of resources, the decision-making process or the medical sovereignty.

\section{Theme 4: End-of-life issues: maintaining futile care or withdrawing treatment}

Three participants specifically addressed the issue of maintaining futile care in their narratives. This issue was also discussed extensively in the focus group transcripts.

One registered ICU nurse (B23) was sanguine: 'I sympathise with the family. The patient is a breadwinner but according to the Bible, we must depart.' Another nurse (FG1) in the focus group interviews said: 'You're not adding value, just prolonging suffering. The patient is still going to die.'Yet another (FG2) said: 'They don't want to feel guilty!'

It is moot whether these nurses experienced no emotional distress or whether they were losing their capacity for caring as a result of moral distress. ${ }^{[3]}$ Compassion fatigue is commonly found in staff who are regularly faced with critical illness, death and assisting families to deal with grief. ${ }^{[15]}$

One focus group member (FG3) expressed concern about the medical team's inability to come to an agreed-upon decision: '... orders are not clear: one will say "no escalation", the other will say "give voluven" (a plasma volume replacement); there is no clear-cut end. You don't know because there is no handover from one to the other.'

One ICU nurse (C4) recounted her distress when a patient who had been declared brain dead was prescribed IV inotropes by a consultant. She asked why this was being done but failed to receive a satisfactory answer, 'delaying the patient and causing more unnecessary labour'.

It is difficult to predict patient survival accurately. Active care given to a patient who has no hope of recovering prolongs the dying process and creates moral distress, raises false hopes for the family and is said to contribute to an extended grieving period. ${ }^{[31]}$ Gutierrez ${ }^{[14]}$ asserts that when doctors give erroneous information about a patient's prognosis, nurses experience moral conflict and distress. Schluter et al. ${ }^{[25]}$ state that moral distress is caused by providing poorquality or futile care, unsuccessful advocacy and unrealistic hope.

Three nurses described the distress they felt when a decision was made to hasten death. One ICU nurse (B16) recounted how she was told to give 'high doses of morphine and Dormicum.' 'He was intact mentally, just not recovering physically, and aware of being killed or left to die because we're not going to do anything more for them. This is murder!' Similarly, a patient who was unable to be weaned from a ventilator was 'looking with fear; he knew it was a death sentence. He was detached from the ventilator and then bradycardic til asystolic.' A particularly poignant story was told by an ICU nurse (B14): 'Patient was fully conscious, but the family asked that treatment be terminated, citing the patient's "living will". The consultants "ordered" that the endotracheal tube be removed but wouldn't do this themselves and delegated the task to a "junior doctor". It was unfair for the junior doctor to be given an order that will definitely 
kill.'The nurse said: 'I just switched off my mind. I went off for 2 days but I was hurting.'

A similar narrative told of a young foreign patient who was extensively burned. He remained in hospital, ventilated, for 3 months but could not be weaned off the ventilator. He was finally transferred to specialist unit but soon died. The nurse attributed the delay in transfer to racism and xenophobia, and felt 'very bitter; we failed the patient and denied him right to treatment' (B18)

The focus group transcripts revealed another response: two nurses who disagreed with the decision to terminate active care told of undermining the process. The first (FG1) said: 'I will treat the patient - even if it's not on the chart; even if it's with a little glucose. I will not slow down.' In the same group, a nurse (FG5) said they would continue with treatment: '. .. even inotropes, but you forget about the colleague coming on duty. It's going to be a shock to find out that there was really no blood pressure.'

Two nurses felt that the process of asking the family for consent to harvest organs was traumatic and poorly managed. One registered nurse (B5) said: II was so disturbed ... I shouted at the lady who came to enquire about organ donation. I shouted at the doctor - told him to come and explain to the relatives. They must not pressurise.'

Once again, the lack of interdisciplinary communication and agreement regarding the care of the patient and decisions as to the outcomes envisaged is demonstrated. Nurses were angry and resentful, or in some cases resorted to passive (and frightening) means of undermining the process. The outcome of their behaviour might well further disrupt team cohesion and lead to distrust and alienation.

\section{Theme 5: Support}

Fifteen participants explicitly stated that no support was offered by management; they felt that this should be given and said that the poor support was likely to affect their care of patients: '... things that we get exposed to are deep, but there is nothing. You survive, then you become desensitised. You admit another patient, carry on, no debriefing, none expected. Someone should say “How do you feel? In future how should we deal with this?"' (ICU nurse C15). One said that counselling had been provided after a particularly traumatic incident but that this hadn't helped; another one said that counselling had been offered but they were unable to attend on the day of the appointment.

Four derived some comfort from the belief that it was God's decision as to whether the patient lived or died. One person stated that prayer helped. Most discussed the situation that distressed them with their colleagues.

Participants offered suggestions as to what they believed should be done: 'Give us stress management' (B28); '... we should be debriefed. Just to talk to someone and offload' (FG1); 'Offer some EOL training. Junior nurses are the most affected' (B12).

The effect of witnessing or experiencing extreme stress is a key aetiological factor in post-traumatic stress disorder. Vicarious traumatisation is recognised in those who care for people who have been exposed to a major stressor, and describes the cumulative transformative effect on the caregiver. ${ }^{[32]}$ The effects appear similar to those of post-traumatic stress disorder and affect the sufferer's frame of reference, identity, sense of safety, trust, self-esteem, intimacy and sense of self-control. The continuing exposure to fraught situations, the effects of violence and trauma, and distress may cause emotional numbing and even result in the caregiver choosing to leave the practice area or even the profession. ${ }^{[3,9,14,16]}$ Emotional support, regular debriefing and, if required, referral to a professional counsellor may assist the nurse to engage in reflective practice, encourage self-awareness and self-care and offer collegial support to other practitioners in the intensive care arena.

\section{Discussion}

In this study, considerable distress was evoked by the perceived morality of the situation or the treatment decisions and their influence on nursing care. The situations or issues identified which caused moral distress were: perceived collegial incompetence or inexperience; a shortage of resources, particularly staff; poor communication and consultation practices; and concerns around EOL (maintaining futile care or withdrawing treatment, and support).

Many of the narratives gave details of distress experienced by the participants when decisions were made to withdraw or withhold active treatment, when they felt conflicted about the decisions, when they were expected to institute the process of withdrawing treatment, and when they were told of a decision without having been party to the discussion.

Of note was that, apart from discussions with their colleagues, the nurses perceived that they were totally unsupported. Management was viewed as uncaring and of the 33 written responses, five explicitly stated that there was no support or debriefing offered. More than half of the participants urged that counselling and debriefing sessions be arranged by hospital management. Supervisors were also not seen as helpful, while they in turn were conscious that their ability to supervise staff and students was compromised by the pressure of work and the inadequacy of many of the staff they supervised. No mention was made of multidisciplinary team support, and unit supervisory support was only mentioned by one participant supervisor who stated that she made a point of trying to assist students. Four cited collegial support as helpful and one person stated that she had called a climate meeting to discuss a particularly distressing situation.

God and prayer were also viewed as a means of comfort for both the patient families and the nurse. Many emphasised that simply writing their stories had helped them deal with emotions that had lain dormant for some time.

It appears that participants were profoundly affected by their experiences; they felt guilty, humiliated, inadequate, angry and, in one case, bitter. Many wrote long, detailed narratives about the situation, and one person mentioned that they still dreamt about a particular situation. This accords with the literature surveyed, which describes how distress was experienced as feelings of powerlessness, subordination and compromised efficiency that might engender passivity and blunted moral sensitivity. ${ }^{[33]}$ The possible effects of unresolved moral distress are significant, and include: job dissatisfaction, burnout and turnover of staff. This, in an already stretched environment with poor resources and staff shortages, has grave implications for healthcare.

SA's history is that of a racially and ethnically divided, patriarchal society with marked cultural, social and educational divisions between the diverse groups. Medicine as a profession still enjoys status not accorded to nursing, with the profession predominantly represented by advantaged, university-educated, white and Asian males; the nursing profession still primarily comprises black women who have diplomas in nursing. A social hierarchical system persists, and culturally, black women are socialised to be submissive and 
defer to men or people in authority. This is not peculiar to SA and many studies attest to non-assertive behaviour of nurses in the workplace. ${ }^{[3436]}$ Nurse education and socialisation may stress autonomy and patient advocacy but, in the clinical situation, it is often difficult to practise these attributes. Consequently, patterns of passivity or submission to medical authority prevail, leading to tension between what is believed or held important and what is culturally and socially the norm. Narratives and focus group transcripts revealed that patient advocacy was tentative but abandoned when the nurse's voice opposed that of the doctor. Most felt that they were forced to accept the situation; some addressed the problem after the event by challenging the person they perceived as incompetent or referring the issue to management. Some felt angry or devalued and responded passively or aggressively, but seldom assertively.

Participants wrote of termination or withdrawal of treatment as a cause of moral distress. Many suggested how the decisions or interventions should have been made. Some stated that they were actually able to do what was required but chose not to do so. One or two were able to comment on or question the decision after the occurrence. Recommendations as to the correct treatment, procedure or intervention might be proffered but, when not adopted, no further action was taken - even when this inaction was to the patient's detriment; as one nurse said: 'I was submissive, I did nothing!'(C3). The lack of trust, inadequate communication between disciplines; absence of collegiality, restricted institutional and mutual support and the continued submission of nurses within the ICU is a reflection of a divided society in microcosm.

\section{Conclusion}

The divisions evident in SA society, with its history of class, race, professional and gender inequality are mirrored and perhaps exacerbated in the ICU. A history of trauma, denigration and disenfranchisement that affects self-esteem, speaking out (and the right to speak), listening and acting shapes this microcosm.

The primacy of life and death issues prevents the forming of 'normalising' relationships (collegial, cooperative and collaborative) and addressing the consequences of this history. Traditional patriarchal norms and the hierarchical nature of the doctornurse relationship are reinforced, constraining the autonomy and accountability of the nurse and contributing to moral distress and burnout.

\section{Recommendations}

Support needs to be offered on a regular basis for nurses practising in the ICU.This should be based on a non-directive'story-telling'format and allow for debriefing and affirming in a safe, group context. At the same time, nurses' self-reflection and self-awareness should be encouraged; this could be done in the group. Gradually, assertiveness education and training could be addressed in workshops, supervision meetings with individual staff members, and continuing professional development (CPD) presentations and staff meetings. Skills could be practised in a safe, supportive group environment. Encouraging a change in attitudes and behaviour affords a space to 'try out' and deconstruct the norm - instituting social and professional transformation. Interprofessional collaboration should be promoted, for example, nurses should attend daily ward rounds and be urged to contribute to the discussion and planning of patient care. Enhancement of collaboration, nurse autonomy and interdisciplinary respect is likely to promote an appreciation of nursing input and a decrease in the instances of moral distress.

\section{References}

1. Jameton A. Nursing practice: The ethical issues. Englewood Cliffs, New Jersey, USA: Prentice Hall, 1994.

2. Gastmans C. Nursing ethics perspectives on end-of-life care. Nurs Ethics 2012;19(5):603-604 [http://dx.doi.org/10.1177/0969733012453234]

3. American Association of Critical-Care Nurses (AACN). Moral distress position statement. Aliso Viejo, California, USA: AACN, 2006.

4. Wilkinson JM. Moral distress in nursing practice: Experience and effect. Nurs Forum 1987;23(1):16-29. [http://dx.doi.org/10.1111/j.1744-6198.1987.tb00794.x]

5. Fowler MD. Moral distress and the shortage of critical care nurses. Heart Lung 1989;18(3):314315.

6. Hamric AB. Moral distress in everyday ethics. Nurs Outlook 2000;48(5):199-201. [http://dx.doi. org/10.1067/mno.2000.110564]

7. Oberle K, Hughes D. Doctors' and nurses' perceptions of ethical problems in end of life decisions. J Adv Nurs 2001;33(6):707-715. [http://dx.doi.org/10.1046/j.13652648.2001.01710.x]

8. Van Soeren M, Miles A. Commentary: The role of teams in resolving moral distress in intensive care unit decision-making. Crit Care 2003;7:217-218. [http://dx.doi.org/10.1186/ cc2168]

9. Elpern EH, Covert B, Kleinpell R. Moral distress of staff nurses in a medical intensive care unit. Am J Crit Care 2005;14(6):523-530.

10. Lützén K, Dahlqvist V, Eriksson S, Norberg A. Developing the concept of moral sensitivity in health care practice. Nurs Ethics 2006;13(2):187-196.

11. Hamric AB, Davis WS, Childress MD. Moral distress in health care professionals: What is it and what can we do about it? Pharos Alpha Omega Alpha Honor Med Soc 2006;69(1):16-23.

12. Langley G, Schmollgruber S, Fulbrook P, Albarran J, Latour J. South African critical care nurses' views on end-of-life decision-making and practices. Nurs Crit Care 2013;19(1):9-17. [http:// dx.doi.org/10.1111/nicc.12026]

13. Corley MC. Moral distress of critical care nurses. Am J Crit Care 1995;4(4):280-285.

14. Gutierrez KM. Critical care nurses' perceptions of and responses to moral distress. Dimens Crit Care Nurs 2005;24(5):229-241.

15. Wee D, Myers D. Compassion satisfaction, compassion fatigue and critical incident stress management. In J Emerg Health 2003;5(1):33-37.

16. Corley MC, Elswick RK, Gorman M, Clor T. Development and evaluation of a moral distress scale. J Adv Nurs 2001;33(2):250-256.

17. Corley MC, Minick P, Elswick RK, Jacobs M. Nurse moral distress and ethical work environment Nurs Ethics 2005;12(4):381-390.

18. Fry ST, Harvey RM, Hurley AC, Foley BJ. Development of a model of moral distress in military nursing. Nurs Ethics 2002;9(4):373-387.

19. Nathaniel AK. Moral reckoning in nursing. West J Nurs Res 2006;28(4):439-448. [http://dx.doi. org/10.1177/0193945905284727]

20. Keeton G. Inequality in South Africa. J Helen Suzman Found 2014;1(74):26-31.

21. De Beer J, Brysiewicz J, Bhengu B. Intensive care nursing in South Africa. S Afr J Crit Care 2011;27(1):6-10.

22. Delobelle P, Onya H, Langa C, Mashamba J, Depoorter AM. Advances in health promotion in Africa: Promoting health through hospitals. Global Health Promotion 2010;17(2):33-36. [http:// dx.doi.org/10.1177/1757975910363929]

23. McNeilly L. WHO examines disabilities worldwide: Report outlines prevalence, barriers and health care issues. World Beat 2011;16(9):38.

24. McLendon $\mathrm{H}$, Buckner EB. Distressing situations in the intensive care unit: A descriptive study of nurses'responses. Dimens Crit Care Nurs 2007:26(5):199-206. [http://dx.doi.org/10.1097/01. DCC.0000286824.11861.74]

25. Schluter J, Winch S, Holzhauser S, Henderson A. Nurses' moral sensitivity and hospital ethical climate: A literature review. Nurs Ethics 2008;15(3):304-321. [http://dx.doi. org/10.1177/0969733007088357]

26. Pauly B, Varcoe C, Storch J, Newton L. Registered nurses' perceptions of moral distress and ethical climate. Nurs Ethics 2009;16(5):561-573. [http://dx.doi. org/10.1177/0969733009106649]

27. Lincoln Y, Guba E. Naturalistic inquiry. Beverly Hills, USA: Sage, 1985.

28. Patton MQ. Qualitative Research and Evaluation Methods. 3rd ed. Thousand Oaks, USA: Sage, 2002.

29. Koch T. Establishing rigour in qualitative research: The decision trail. J Adv Nurs 1994;19(5):976986.

30. Frick $S$, Uehlinger $D$, Zenklusen M. Medical futility: Predicting outcome of intensive care unit patients by nurses and doctors - A prospective comparative study. Crit Care Med 2003;31(2):456-461. [http://dx.doi.org/10.1097/01.CCM.0000049945.69373.7C]

31. Meltzer LS, Huckabay LM. Critical care nurses' perceptions of futile care and its effect on burnout. Am J Crit Care 2004;13(3):202-208.

32. Trippany RL, White Kress VE, Wilcoxon SA. Preventing vicarious trauma: What counsellors should know when working with trauma survivors. J Couns Dev 2004;82(1):31-37. [http:// dx.doi.org/10.1002/j.1556-6678.2004.tb00283.x]

33. De Veer AJ, Francke AL, Struijs A, Willems DL. Determinants of moral distress in daily practice: A cross sectional correlational questionnaire survey. Int J Nurs Stud 2013;50(1):100-108. [http:// dx.doi.org/10.1016/j.jijnurstu.2012.08.017]

34. Timmins F, McCabe C. How assertive are nurses in the workplace? J Nurs Manage 2005;13(1):6167. [http://dx.doi.org/10.1111/j.1365-2834.2004.00492.x]

35. Timmins F, McCabe C. Nurses' and midwives' assertive behaviour in the workplace. J Adv Nurs 2005;51(1):38-45. [http://dx.doi.org/10.1111/j.1365-2648.2005.03458.x]

36. Butters KJ. A qualitative study of the ethical practice of newly graduated nurses working in mental health. Thesis. New Zealand: Massey University, 2008. 